\title{
COMPLEX SYMMETRIC WEIGHTED COMPOSITION LAMBERT TYPE OPERATORS ON $L^{2}(\Sigma)$
}

\author{
M. R. JABBARZADEH AND M. MORADI
}

Abstract. In this paper we obtain the polar decomposition and the Aluthge transform of a weighted composition Lambert type operator $M_{w} E M_{u} C_{\varphi}$ on $L^{2}(\Sigma)$. In addition, we study the complex symmetry of these types of operators induced by triple $(w, u, \varphi)$.

Mathematics subject classification (2010): Primary 47B20, Secondary 47B38.

Keywords and phrases: Lambert Type operator, conditional expectation operator, composition, polar decomposition, complex symmetry.

\section{REFERENCES}

[1] P. S. Bourdon and S. Waleed Noor, Complex symmetry of invertible composition operators, J. Math. Anal. Appl. 429 (2015), 105-110.

[2] J. T. CAMPBell AND W. E. HornOR, Localising and seminormal composition operators on $L^{2}$, Proc. Roy. Soc. Edinburgh Sect. A 124 (1994), 301-316.

[3] Y. Estaremi And M. R. JABBARZADEH, Weighted composition Lambert type operators on $L^{p}$ spaces, Mediterr. J. Math. 11 (2014), 955-964.

[4] Y. Estaremi AND M. R. JabBarzadeh, Weighted lambert type operators on $L^{p}$-spaces, Oper. Matrices 7 (2013), 101-116.

[5] S. R. Garcia, E. Prodan And M. Putinar, Mathematical and physical aspects of complex symmetric operators, J. Phys. A 47 (2014), 353001, 54 pp.

[6] S. R. Garcia And M. Putinar, Complex symmetric operators and applications I, Trans. Amer. Math. Soc. 358 (2006), 1285-1315.

[7] S. R. Garcia And M. Putinar, Complex symmetric operators and applications II, Trans. Amer. Math. Soc. 359 (2007), 3913-3931.

[8] S. R. Garcia AND W. Wogen, Some new classes of complex symmetric operators, Trans. Amer. Math. Soc. 362 (2010), 6065-6077.

[9] J. J. GRobler AND B. DE PAGTER, Operators representable as multiplication conditional expectation operators, J. Oper. Theory 48 (2002), 15-40.

[10] P. V. HAI AND L. H. KHOI, Complex symmetry of weighted composition operators on the Fock space, J. Math. Anal. Appl. 433 (2016), 1757-1771.

[11] J. D. Herron, Weighted conditional expectation operators, Oper. Matrices 1 (2011), 107-118.

[12] T. Hoover, A. LAmberT AND J. Quinn, The Markov process determined by a weighted composition operator, Studia Math. LXXII (1982), 225-235.

[13] M. R. JABBARZADEh AND Y. EstAREMI, Essential norm of substitution operators on $L^{p}$ spaces, Indian J. Pure Appl. Math. 43 (2012), 263-278.

[14] M. R. JABBARZADEH, Conditional multipliers and essential norm of $u C_{\varphi}$ between $L^{p}$ spaces, Banach J. Math. Anal. 4 (2010), 158-168.

[15] A. LAmbert, $L^{p}$ multipliers and nested sigma-algebras, Oper. Theory Adv. Appl. 104 (1998), $147-$ 153.

[16] M. M. RaO, Conditional measure and applicationc, Marcel Dekker, NewYork, (1993).

[17] M. WANG AND X. YAO, Complex symmetry of weighted composition operators in several variables, Internat. J. Math. 27 (2016) 1650017, 14 pp. 